University of Nebraska - Lincoln

DigitalCommons@University of Nebraska - Lincoln

1965

\title{
Dual Low Dosage Applications of Heptachlor for Control of the Imported Fire Ant
}

\author{
C. S. Lofgren \\ USDA
}

C. E. Stringer, Jr.

USDA

F. J. Bartlett

USDA

W. A. Banks

USDA

W. F. Barthel

USDA

Follow this and additional works at: https://digitalcommons.unl.edu/entomologyother

Part of the Entomology Commons

Lofgren, C. S.; Stringer, Jr., C. E.; Bartlett, F. J.; Banks, W. A.; and Barthel, W. F., "Dual Low Dosage Applications of Heptachlor for Control of the Imported Fire Ant" (1965). Entomology Papers from Other Sources. 21.

https://digitalcommons.unl.edu/entomologyother/21

This Article is brought to you for free and open access by the Entomology Collections, Miscellaneous at DigitalCommons@University of Nebraska - Lincoln. It has been accepted for inclusion in Entomology Papers from Other Sources by an authorized administrator of DigitalCommons@University of Nebraska - Lincoln. 


\title{
DUAL LOW DOSAGE APPLICATIONS OF HEPTACHLOR FOR CONTROL OF THE IMPORTED FIRE ANT
}

\author{
C. S. Lofgren, C. E. Stringer, JR., F. J. Bartlett, W. A. Banks, \\ AND W. F. BARTHEL \\ Plant Pest Control Division, Agricultural Research Service, \\ U. S. Department of Agriculture, Gulfport, Mississippi
}

Control of the imported fire ant, Solenopsis saevissima richteri (Forel), with two applications of heptachlor at dosages of $1 / 4$ or $1 / 2$ pound per acre applied at intervals of 3 or 6 months was reported by Lofgren et al. (1961). Murphy et al. (1962) reported that soil residue following two successive $1 / 4$ pound per acre treatments of heptachlor is equivalent after 10 months to the residue following a single 1 pound per acre treatment.

The purpose of this report is to present further data from subsequent small and large plot tests with dual applications of heptachlor.

SMALl PLot TESTS: Two series of tests were initiated, one in December 1959 and one in April 1960. Formulations on 16-30 mesh, AARVM attapulgite granules containing $7 \%$ deactivator, $10 \%$ solvent, and 2.5 or $5.0 \%$ heptachlor were used. They were applied with a Jeep-mounted Buffalo turbine blower at the rate of 10 pounds per acre on duplicate, randomized, 1-acre plots. The time interval between treatments was varied. The results are presented in Table 1.

In Series I, two applications of $1 / 8$ or $1 / 4$ pound per acre of heptachlor applied 6 months apart resulted in $100 \%$ control of imported fire ants after 12 months. The $1 / 8$ pound per acre plots were reinfested after 24 months $(82 \%$ control). The $1 / 4$ pound per acre plot appeared reinfested after 24 months but at 30 months it again showed $100 \%$ control. Two applications of $1 / 4$ pound heptachlor per acre, applied 12 months apart, gave complete control through 30 months. In these plots the initial single application had given $100 \%$ control at the 9-month count. Two applications of $1 / 8$ pound per acre applied 12 months apart gave very good control after 18 months $(98 \%)$, but the plots were becoming reinfested at the 24-month count. A single $1 / 8$ pound per acre application gave a maximum of $89 \%$ control, and one application of $1 / 4$ pound per acre gave $93 \%$ control.

In Series II, two treatments of $1 / 8$ pound per acre of heptachlor, applied 3 months apart, resulted in complete control after 6 to 8 months, but the control had decreased to $98 \%$ and $76 \%$ respectively after 12 and 24 months. Two $1 / 8$ pound per acre applications, spaced 8 months apart, gave a maximum reduction of $98 \%$ after 1 year.

After the $1 / 4$ pound per acre plots had been treated with what was believed to be a $2.5 \%$ granulated heptachlor formulation, it was discovered that the formulation contained only $0.37 \%$ heptachlor. Thus, the actual application rate was approximately $1 / 32$ pound per acre. Early observations showed that some kill was being attained, so the plots were maintained on the regular count schedule and retreatments were made with the same amount of heptachlor. Two treatments, 3 months apart, with $1 / 32$ pound per acre gave a maximum control of $93 \%$ after 8 months. When two applications at the same dosage were applied 8 months apart, the maximum reduction in active mounds was $63 \%$ after 12 months. 


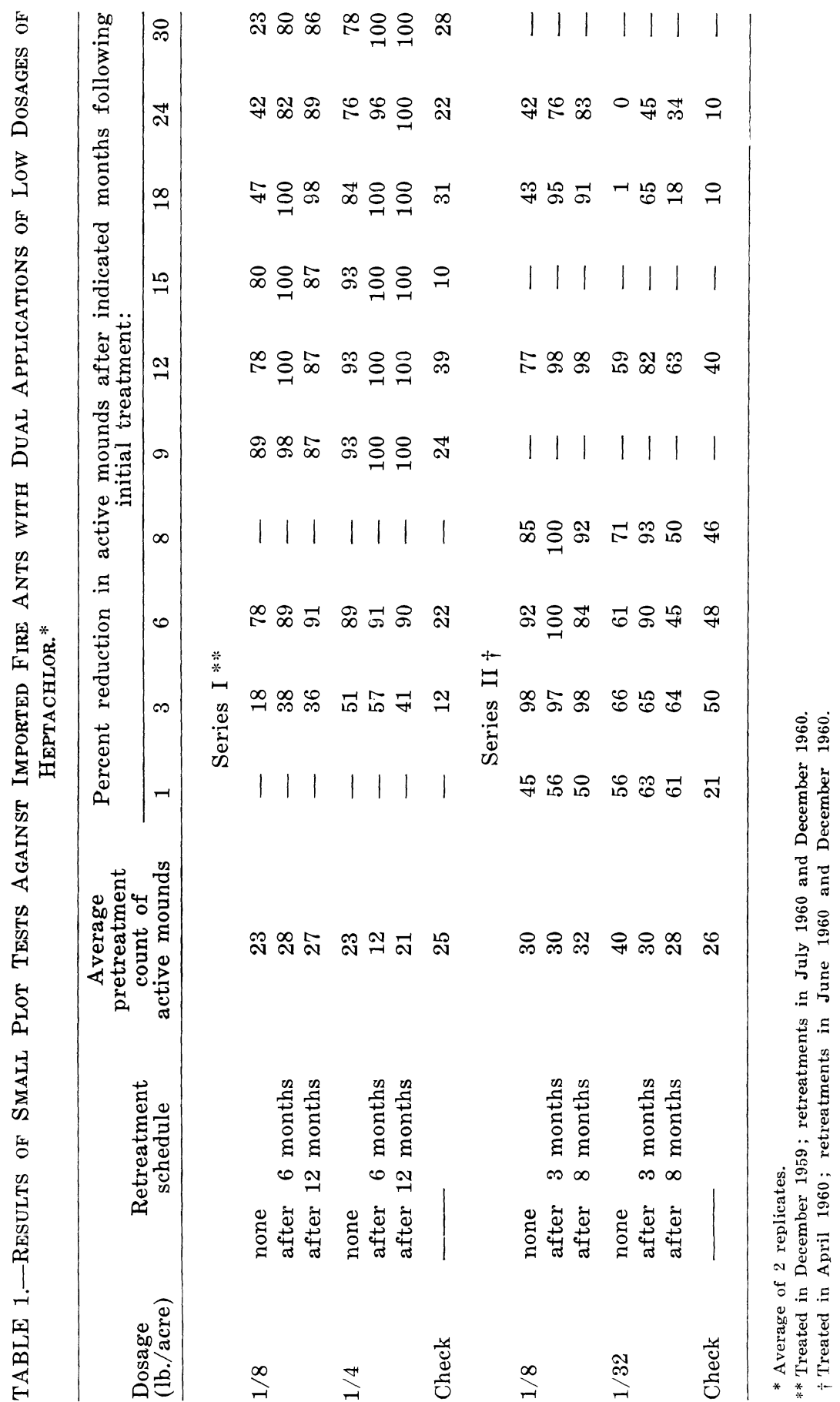


In addition to the preceding tests, a dual application of $1 / 4$ pound per acre of heptachlor was employed as the standard in three other experiments. In each test $100 \%$ control was obtained 1 year after the initial application. The interval between treatments ranged from 2 to 8 months. Two of the treatments ( 2 to 7 months between treatments) were becoming reinfested after $1 \frac{1 / 2}{2}$ years, while the third (8-month interval) was free of ants after 2 years.

LARGE PLOT TESTS: In the fall of 1959, an area north of Gulfport, Mississippi was selected for a test to evaluate aerial treatments of (1) dual applications of $1 / 4$ and $1 / 2$ pound per acre of heptachlor and (2) various bulk application rates at each dosage level. The area was subdivided into 6 plots, 5 of which were about 180 acres in size and 1 about 120 acres. The ground cover on each plot consisted of varying proportions of bahiagrass, idle or heavily weeded land, and pine forest-portions of each plot were low and wet. Four subplots, or count areas, were located within the boundaries of each plot; three were approximately 2 acres in size $(200 \mathrm{x}$ $400 \mathrm{ft}$.) and were in open areas, usually pasture, and the fourth was approximately 1 acre $(200 \times 200 \mathrm{ft}$.) and was located in a wooded area. The subplots were located in the plots in such a manner that all the plane application swaths would cross at least one of them. The pretreatment counts of active ant mounds on the subplots ranged from 7 to 66 .

The treatments evaluated are listed in Table 2. The first application was made in November 1959 with a $450 \mathrm{hp}$ Stearman and the second in May 1960 with an AG-2. Both were equipped with Swathmaster distributors. The planes were flown on a 60 -foot swath which theoretically allowed a 5 to 10 -foot overlap of the swaths. The $10 \%$ heptachlor employed on the plot treated with $21 / 2$ pounds per acre of $10 \%$ granules was made with a finer mesh granule (24-48 mesh vs. 16-30 mesh for other formulations). This was done to insure easier calibration and more uniform flow of the granules at this low application rate.

The results of the test (Table 2) show that after 12 months complete control had been attained on the plots treated with $1 / 2$ pound per acre at bulk application rates of 10 pounds per acre of $5 \%$ granules (Plot 1 ) and 5 pounds per acre of $10 \%$ granules (Plot 4). Complete control was also obtained with $1 / 4$ pound per acre when it was applied at the bulk rate of 10 pounds of $2.5 \%$ granules. After 24 months some of the subplots on all of the plots were becoming reinfested with incipient imported fire ant colonies; however, the percentage reduction in active mounds was still very high $(92$ to $100 \%)$, with the exception of one subplot in the area that had been treated with 5 pounds of $10 \%$ granules $(57 \%)$.

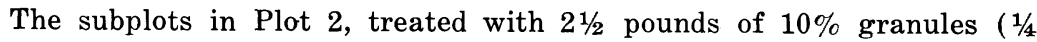
lb. heptachlor per acre), were all free of ants after 9 months, but after 12 months one colony was found on one of the subplots. After 2 years all of the subplots except the one in the woods were heavily reinfested with incipient colonies. As stated before, a 24-48 mesh granule was used instead of the regular 16-30 mesh. Other tests have indicated that heptachlor, formulated on fine mesh granules, does not provide as long a residue as that formulated on large or coarse mesh granules. This fact probably explains partially the reason for the faster reinfestation on this plot.

Plot 3 was originally scheduled to be treated with 5 pounds per acre 


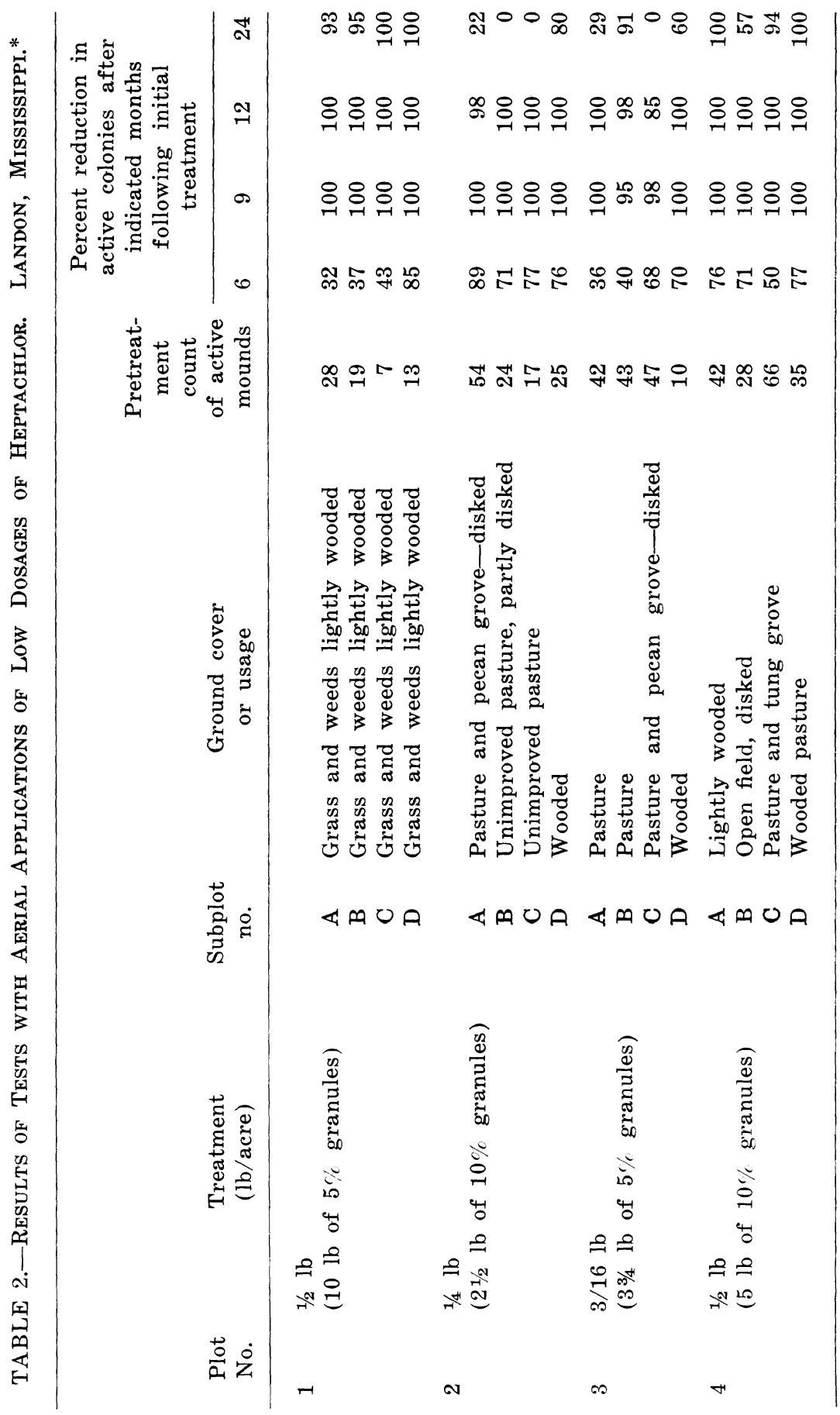




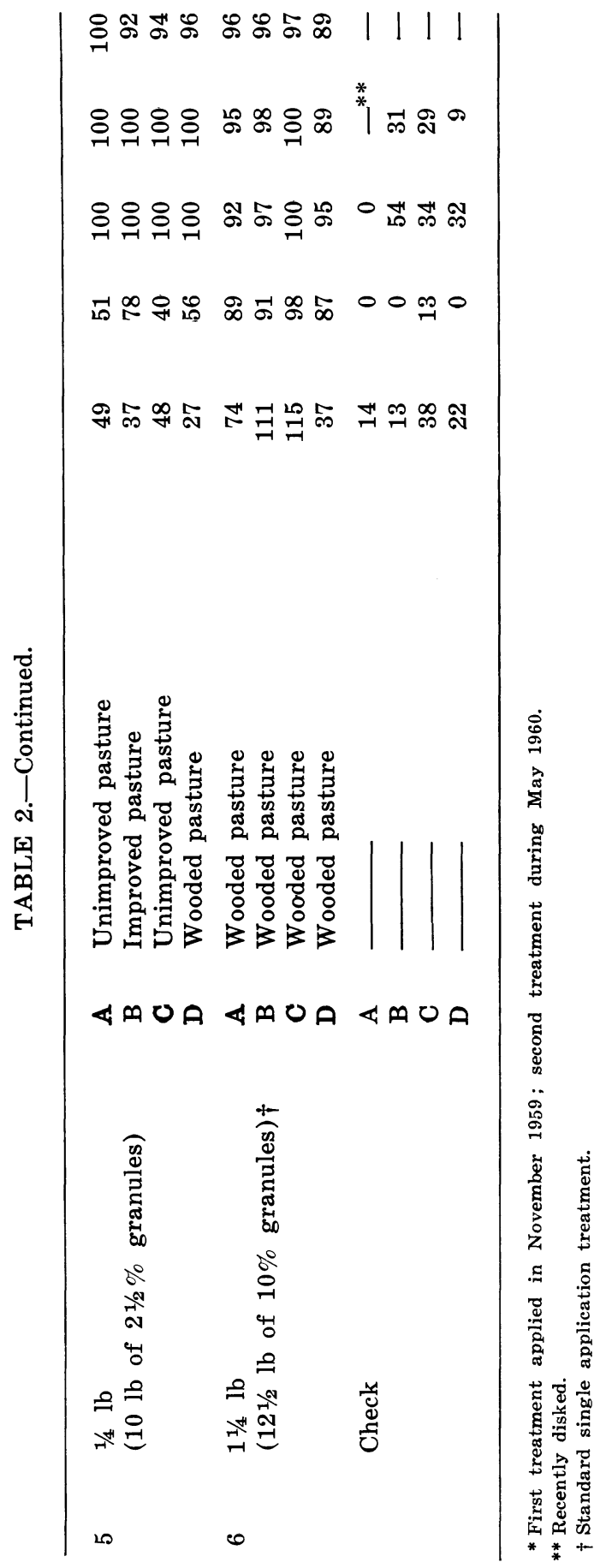


of $5 \%$ heptachlor granules ( $1 / 4$ pound per acre of actual insecticide). Due to calibration difficulties, the actual application rate was $3 / 16$ pound per acre. After 12 months, 2 of the subplots had shown complete control, while the other 2 subplots showed $85 \%$ and $98 \%$ control. After 24 months the control was very erratic and ranged from 0 to $91 \%$. The poor control was undoubtedly associated with the lower dosage rate and the possibility that this lower dosage was associated with non-uniform, or uneven distribution, of the granules from the airplane. Plot 6, which was treated with one application of $121 / 2$ pounds of $10 \%$ heptachlor granules per acre, or $11 / 4$ pounds of heptachlor per acre, had only one of the 4 subplots within it free of ants after 12 months. The control on the other 3 subplots ranged from $89 \%$ to $98 \%$. After 24 months the one subplot which had been free of ants was becoming reinfested, while the other 3 plots maintained about the same control. The control on the 4 subplots ranged from $89 \%$ to $97 \%$.

Conclusions: The results of these tests show that eradication of the imported fire ant from a given area can be obtained with two applications of heptachlor at dosages of $1 / 4$ or $1 / 2 \mathrm{lb}$. per acre applied at intervals of 6 to 12 months. The following factors must be controlled to obtain maximum effectiveness of the treatments:

1. The concentration of the heptachlor on the granulated formulations should be adjusted to allow sufficient bulk application rate to insure good distribution on the ground.

2. The heptachlor should be formulated at a relatively low concentration on a carrier of optimum particle size in order to yield the highest possible soil residue.

3. The equipment employed to apply the treatments must have a uniform delivery rate and swath pattern.

4. All precautions must be taken to insure that the entire surface area receives treatment.

\section{Literature Cited}

Lofgren, C. S., V. E. Adler, and W. F. Barthel. 1961. Effect of some variations in formulation and application procedure on control of the imported fire ant with granular heptachlor. J. Econ. Ent. 54: 45-47.

Murphy, R. T., W. F. Barthel, and C. S. Lofgren. 1962. Residual studies in connection with successive applications of heptachlor for imported fire ant eradication. J. Agr. Food Chem. 10:5-7.

The Florida Entomologist 48(4) 1965 